OPEN ACCESS

Edited by:

Donato Angelino,

University of Teramo, Italy

Reviewed by:

Cinzia Ferraris,

University of Pavia, Italy

Giorgia Vici,

University of Camerino, Italy

*Correspondence:

Ingrid Hoffmann

ingrid.hoffmann@mri.bund.de

Specialty section

This article was submitted to

Nutritional Epidemiology,

a section of the journal

Frontiers in Nutrition

Received: 26 November 2020

Accepted: 22 January 2021

Published: 12 February 2021

Citation:

Koch F, Hoffmann I and Claupein E (2021) Types of Nutrition Knowledge,

Their Socio-Demographic Determinants and Their Association With Food Consumption: Results of the NEMONIT Study.

Front. Nutr. 8:630014.

doi: 10.3389/fnut.2021.630014

\section{Types of Nutrition Knowledge, Their Socio-Demographic Determinants and Their Association With Food Consumption: Results of the NEMONIT Study}

\author{
Franziska Koch, Ingrid Hoffmann* and Erika Claupein \\ Institute for Nutritional Behaviour, Max Rubner Institute, Karlsruhe, Germany
}

Objectives: To investigate nutrition knowledge in the German population, its determinants and its association with food consumption.

Methods: Data were obtained from the NEMONIT study $(2014 / 15, n=1,505$, participants' age: 22-80 years). Nutrition knowledge was measured using the consumer nutrition knowledge scale (CoNKS) in a computer-assisted telephone interview. Two 24-h recalls were conducted to assess food consumption, which was evaluated using the Healthy Eating Index-NVS II.

Results: Areas for knowledge enhancement were the understanding of health benefits of fruit and vegetable consumption, the concept of a balanced diet and saturated fatty acids. Nutrition knowledge was higher among females, younger and high socio-economic status participants. Correlations between nutrition knowledge and a favorable diet were significant but low. Analyses of types of nutrition knowledge yielded similar results for procedural knowledge and knowledge on nutrients but not for knowledge on calories.

Conclusions: Areas for knowledge enhancement were identified, but an increase in nutrition knowledge alone seems unlikely to result in large improvements of dietary behavior.

Keywords: nutrition knowledge, types of knowledge, food consumption, dietary recommendations, healthy eating, NEMONIT

\section{INTRODUCTION}

The factors influencing an individual's food choice are numerous and include, amongst others, habits, practical skills, cultural or environmental factors as well as motives like taste, convenience or price (1-3). Nutrition knowledge might also be one of several factors influencing food choice. Given the abundance of possibilities for food choices in Western societies, a certain level of knowledge might be necessary to make a healthy selection. Since food consumption of Western populations is often not in line with dietary recommendations (4-7), knowledge dissemination and nutrition education are common-but usually not evaluated-strategies of public health initiatives aiming to change dietary behavior. 
As reported in a systematic review by Spronk et al. (3), it is well documented in international studies that nutrition knowledge is influenced by age, sex, and socio-economic status. However, the direction of the relationship between age and nutrition knowledge was contradictory across studies. While Hendrie et al. (8) observed a positive relationship, Dickson-Spillmann and Siegrist (9) and Dickson-Spillmann et al. (2) observed a negative relationship and Parmenter et al. (10) reported a curvilinear relationship, where middle-aged groups had a higher knowledge than younger and older participants. It should be noted though that the studies differ substantially in how they defined the age groups, thus limiting comparability. With regard to the association of nutrition knowledge and food consumption the results are also inconclusive. Although the review by Spronk et al. (3) shows that the majority of studies found significant associations between higher nutrition knowledge and healthier food consumption, especially higher fruit and vegetable consumption, these associations were rather weak.

A limitation of previous studies is the challenging measurement of nutrition knowledge. The General Nutrition Knowledge Questionnaire (GNKQ) has been well studied, validated, and adapted to different populations (11-15), but is far too long to be used as one of many instruments in a population-wide survey. Although many recent studies address the development and validation of questionnaires for specific nutrition knowledge areas (especially sports nutrition knowledge) or specific populations (e.g., adolescents, athletes) [e.g., (16-19)], only few validated instruments exist to measure nutrition knowledge in large population surveys.

Instruments that cover different types of nutrition knowledge are also rare (3). Some authors argue that a differentiation between declarative nutrition knowledge and procedural nutrition knowledge might be a promising approach for future research $(2,3,20)$. Declarative knowledge is factual knowledge ("knowing that") while procedural knowledge is knowledge of skills and strategies ("knowing how") (2). Dickson-Spillmann et al. (2) developed and validated a short scale on nutrition knowledge (consumer nutrition knowledge scale-CoNKS) which encompasses both types of knowledge.

In Germany, the National Nutrition Survey (NVS) II (7) enquired single aspects of nutrition knowledge and confirmed that women, younger persons, and persons with a higher socio-economic status have higher nutrition knowledge and that persons with higher nutrition knowledge eat more fruit and less meat and alcoholic drinks $(21,22)$. However, to our knowledge, a psychometrically validated instrument has not been applied previously in a population-based survey in Germany. Additionally, most previous studies did not distinguish between different types of knowledge.

Therefore, the aims of the current study were to investigate the declarative and procedural nutrition knowledge in the German population, its determinants and its associations with food consumption based on the NEMONIT study (23) and using the CoNKS (2) as a validated and comparable measurement.

\section{METHODS}

\section{Study Design and Participants}

This cross-sectional analysis is based on the last survey year data of the NEMONIT study (2014/15). NEMONIT was designed as a longitudinal study to assess changes in food consumption and nutrient intake in Germany. Besides the repeated measurement of food consumption, the annual surveys also included questions on specific nutritional topics (e.g., nutrition knowledge) allowing further cross-sectional analyses. A detailed description of NEMONIT has been published previously (23).

The NEMONIT sample ( $n \sim 2,000)$ was recruited from participants of the German National Nutrition Survey (NVS) II (7) who confirmed their interest in taking part in further surveys. Over the course of the survey years, the sample underwent minor changes due to attrition so that in the final NEMONIT round of $2014 / 2015$, a total of 1,572 participants with an age range of 22-80 years were interviewed. In this analysis, participants of whom data of the computer-assisted telephone interview (CATI) and two 24 -h recalls were available, were included $(n=1,508)$. Among those, three respondents with more than two missing items in the nutrition knowledge questions were excluded from the analysis resulting in a total sample of $n=1,505$.

\section{Socio-Demographic Characteristics and Lifestyle Factors}

Information on socio-demographic characteristics and lifestyle factors was obtained in CATIs. Socio-demographic characteristics included sex, age, school education (highest school-leaving qualification, recoded to years spent in school), and socio-economic status (SES). SES was an index based on three characteristics (participants' education, net household income and employment status of the principal earner of the household; possible range: 3-25 points) and categorized into low, medium, or high (21).

With regard to lifestyle factors, questions on specific diets (e.g., vegetarian diet, dieting), self-rated healthiness of the own diet, self-rated health status, and smoking status were included. Body mass index (BMI) was calculated based on self-reported body weight and height and categorized according to the cutoff points provided by the World Health Organization (WHO) (24). Physical activity was assessed by asking participants to state their mild, moderate, and vigorous physical activity in h/week. After bisecting hours of mild activity and doubling hours of vigorous activities, all activities were summed up as single measure for overall physical activity per week. This figure was compared to the WHO recommendation for physical activity (25) and categorized into inactive $(0 \mathrm{~h})$, active below recommendations ( $>0$ and $<2.5$ hours) and active in agreement with the recommendations $(\geq 2.5 \mathrm{~h})$.

\section{Nutrition Knowledge}

Nutrition knowledge was measured using an adapted version of the consumer nutrition knowledge scale (CoNKS) by DicksonSpillmann et al. (2). This scale aims to measure nutrition knowledge in proximity to consumers by using well-known instead of scientific terms and includes both, declarative and 
TABLE 2 | Socio-demographic and lifestyle characteristics of NEMONIT study 2014/15a participants.

\begin{tabular}{|c|c|c|}
\hline & $n$ & $\%$ (Mean, SD) \\
\hline \multicolumn{3}{|l|}{ Sex } \\
\hline Men & 638 & 42.4 \\
\hline Women & 867 & 57.6 \\
\hline \multicolumn{3}{|l|}{ Age } \\
\hline Mean & & $(56.8)$ \\
\hline SD & & $(14.2)$ \\
\hline 22-34 years & 130 & 8.6 \\
\hline $35-50$ years & 370 & 24.6 \\
\hline $51-64$ years & 501 & 33.3 \\
\hline $65-80$ years & 504 & 33.5 \\
\hline \multicolumn{3}{|l|}{ School education } \\
\hline Up to 9 years & 364 & 24.2 \\
\hline 10 years & 503 & 33.4 \\
\hline 12 or 13 years & 638 & 42.4 \\
\hline \multicolumn{3}{|l|}{ SES } \\
\hline Mean & & $(15.0)$ \\
\hline SD & & (3.5) \\
\hline Low & 170 & 11.3 \\
\hline Medium & 768 & 51.0 \\
\hline High & 567 & 37.7 \\
\hline \multicolumn{3}{|l|}{ Specific diet } \\
\hline Vegetarian (incl. pesco-vegetarian) diet & 47 & 3.1 \\
\hline Dieting (e.g., to lose weight or due to an illness) & 106 & 7.0 \\
\hline \multicolumn{3}{|l|}{ Self-rated nutritional behavior } \\
\hline Very healthy & 111 & 7.4 \\
\hline Predominantly healthy & 1,237 & 82.2 \\
\hline Less healthy/not healthy & 155 & 10.3 \\
\hline Missing & 2 & 0.1 \\
\hline \multicolumn{3}{|l|}{ HEI-NVS II } \\
\hline Mean & & $(67.9)$ \\
\hline SD & & $(10.0)$ \\
\hline Good (>88 points) ${ }^{b}$ & 26 & 1.7 \\
\hline In need of improvement (>55 and $\leq 88$ points) ${ }^{b}$ & 1,326 & 88.1 \\
\hline Poor $\left(\leq 55\right.$ points) ${ }^{b}$ & 153 & 10.2 \\
\hline \multicolumn{3}{|l|}{ Body mass index } \\
\hline Mean & & $(26.0)$ \\
\hline SD & & $(4.6)$ \\
\hline Underweight & 16 & 1.1 \\
\hline Normal weight & 681 & 45.2 \\
\hline Preobese & 587 & 39.0 \\
\hline Obese & 221 & 14.7 \\
\hline \multicolumn{3}{|l|}{ Self-rated health } \\
\hline Good & 1,163 & 77.3 \\
\hline Moderate & 301 & 20.0 \\
\hline Poor & 39 & 2.6 \\
\hline Missing & 2 & 0.1 \\
\hline \multicolumn{3}{|l|}{ Physical activity } \\
\hline Inactive & 441 & 29.3 \\
\hline Active, below recommendations & 391 & 26.0 \\
\hline Active, in agreement with recommendations & 654 & 43.5 \\
\hline Missing & 19 & 1.3 \\
\hline
\end{tabular}

(Continued)
TABLE 2 | Continued

\begin{tabular}{lcc}
\hline & $\boldsymbol{n}$ & $\%$ \\
\hline Smoking & & \\
Smoker & 165 & 11.0 \\
Occasional smoker & 42 & 2.8 \\
Ex-smoker & 521 & 34.6 \\
Non-smoker & 777 & 51.6 \\
\hline
\end{tabular}

${ }^{a}$ NEMONIT study, survey year 2014/2015 ( $\left.n=1,505\right)$; SES, socio-economic status (index combining participants' education, net household income, and employment status of the principal earner of the household); HEI-NVS II, Healthy Eating Index of the German National Nutrition Survey II; ${ }^{b} 55$ points $\triangleq 50 \%$ of total points, 88 points $\triangleq 80 \%$ of total points.

scale to measure both, declarative and procedural knowledge, but did not distinguish the knowledge types in their analysis. Dickson-Spillmann et al. (2) did not theoretically distinguish between declarative knowledge on nutrient and calorie content either. However, we assumed that knowledge on nutrients and knowledge on calories could be different types of nutrition knowledge. Since the three subscales were based on content considerations, the results are exploratory in nature.

\section{Food Consumption and Diet Quality}

Food consumption $(\mathrm{g} / \mathrm{d})$ was assessed with two 24 -h recalls conducted on randomly drawn non-consecutive days (at least 1 week apart) by phone using the software EPIC-Soft (26) (renamed GloboDiet in 2014) as described in detail by Gose et al. (23). Energy and nutrient intakes were calculated based on the German Nutrient Database (BLS, version 3.02) (27).

Diet quality was evaluated using the Healthy Eating IndexNVS II (HEI-NVS II) adapted to 24-h recalls. The HEI-NVS II compares ten components of food consumption or nutrient intake [e.g., "fruit/fruit products," "meat/meat products", "fat (\% of energy intake)"] with food-based dietary guidelines of the German Nutrition Society (28) and national reference values for nutrient intake (29). It can take values from 0 to 110 points, whereby higher scores indicate a better agreement with the recommendations. Further information on the HEI-NVS II can be obtained from Gose et al. (23) and Wittig and Hoffmann (30).

\section{Data Analysis}

Descriptive statistics are provided as means with standard deviations (SD) for metric variables and percentages for categorical variables. Since nutrition knowledge was not normally distributed, differences in nutrition knowledge between groups were tested using Mann-Whitney $U$-test or Kruskal-Wallis test as appropriate. Spearman's Rho correlations were calculated to examine the association of nutrition knowledge and its subscales with food consumption and HEI-NVS II. Multiple linear regressions were used to examine whether associations were independent from socio-demographic factors (sex, age in years, SES index).

Data analysis was performed using SAS 9.3 (SAS Institute, Inc.) and level of significance for all analyses was set at $P<$ 0.05 (two-sided). 


\section{RESULTS}

\section{Sample}

Table 2 shows the socio-demographic characteristics and lifestyle factors of the study sample. The study sample includes a higher proportion of females than males. Participants had a mean age of 57 years and the majority achieved higher school education and were assigned to the medium SES class. The percentage of self-defined vegetarians and pesco-vegetarians was 3 and $7 \%$ of the participants were dieting. The majority rated their nutritional behavior as predominantly healthy while the HEINVS II indicates that there is need of improvement in the diet of a large majority of the participants (Table 2).

\section{Nutrition Knowledge}

On average, items of the nutrition knowledge scale were answered correctly by $70 \%$ of the participants. All except one item were answered correctly by more than half of the participants, indicating relatively easy items (in terms of scale construction). Participants' mean was 14.1 points for the CoNKS Total (SD 3.0, IQR 4), 4.9 points for the subscale procedural knowledge (SD 1.6, IQR 2), 4.8 points for knowledge on nutrients (SD 1.4, IQR 1 ), and 4.4 points for knowledge on calories (SD 1.2, IQR 2) (Table 3). The distribution of scores was skewed to the left in all scales (data not shown).

Some areas for knowledge enhancement can be identified when looking at the single items (Table 1). First, the health benefits of fruit and vegetable consumption do not seem to be sufficiently well-known to the general public. Forty two percentage of the participants assumed the following statement to be correct: "To eat healthily, you should eat less fat. Whether you also eat more fruit and vegetables does not matter." Additionally, about one third of the participants thought the statement "The health benefit of fruit and vegetables lies alone in the supply of vitamins and minerals" to be true. Second, deficits in knowledge concerning the meaning of a balanced diet became apparent. About one third of the participants thought the following statements to be true: "A balanced diet implies eating all foods in the same amounts" and "For a healthy nutrition, dairy products should be consumed in the same amounts as fruit and vegetables." Furthermore, about one fifth of the participants thought that "A healthy meal should consist of half meat, a quarter vegetables and a quarter side dishes." Notably, the questions on a balanced diet and on the health benefits of fruit and vegetables received only few "don't know" answers, compared to questions on specific nutrients and calories. This means that participants were confident about their knowledge in this area, although they more often gave wrong answers than in other areas. Third, the question on saturated fatty acids in dairy products vs. vegetable oils revealed large uncertainties in this area (37\% correct answers).

\section{Socio-demographic Characteristics and Nutrition Knowledge}

Nutrition knowledge differed significantly between sociodemographic groups (Table 3). Women had a higher nutrition knowledge than men, except for knowledge on calories. Nutrition knowledge was higher in younger age groups and in groups with higher school education and higher SES. The results were confirmed in multiple linear regressions (data not shown).

\section{Lifestyle Factors and Nutrition Knowledge}

Nutrition knowledge was higher among individuals following a vegetarian diet, having a normal weight and being physically active (Table 4). This also applied to the subscales of procedural knowledge and knowledge on nutrients but not to the scale measuring knowledge on calories (except for sports activities).

The significant results of the bivariate analysis were generally confirmed in multiple linear regressions controlling for sex, age, and SES (data not shown).

\section{Nutrition Knowledge and Food Consumption}

Nutrition knowledge was positively associated with the consumption of cereals/cereal products, vegetables, fruit/fruit products, and dairy products and negatively with the consumption of potatoes/potato products and meat/meat products (Table 5). However, correlations were rather weak with values between -0.14 and 0.12 . Very similar results were observed when analyzing procedural knowledge and knowledge on nutrients separately. Knowledge on calories, however, was not associated with the consumption of cereals/cereal products, vegetables, fruit/fruit products, or meat/meat products.

In multiple linear regressions, the associations between nutrition knowledge and its subscales with consumption of vegetables, fruit/fruit products, dairy products, and meat/meat products were largely confirmed.

\section{Nutrition Knowledge and Diet Quality}

With increasing values on nutrition knowledge, respondents also had increasing values on the HEI-NVS II (Spearman's Rho correlation coefficient: $\left.r_{s}=0.16, p<0.001\right)$. This also applied to the subscales procedural knowledge $\left(r_{s}=0.15, p<0.001\right)$ and knowledge on nutrients $\left(r_{s}=0.16, p<0.001\right)$, but not to knowledge on calories $\left(r_{s}=0.02, p=0.440\right)$. However, correlations were rather weak and in a simple linear regression model, nutrition knowledge explained only 3\% (procedural knowledge: $2 \%$, knowledge on nutrients: $3 \%$ ) of the variance in HEI-NVS II (data not shown).

Similar to nutrition knowledge, HEI-NVS II was higher among women and among groups with higher school education and higher SES. However, HEI-NVS II increased with age while nutrition knowledge decreased with age. Therefore, multiple linear regressions were performed again to examine whether the association between nutrition knowledge and HEI-NVS II was independent of sex, age, and SES (Table 6). The results confirmed an independent association between nutrition knowledge and HEI-NVS II. However, they also showed that SES was no longer a significant predictor of HEI-NVS II when nutrition knowledge was entered into the model. Therefore, nutrition knowledge may partly mediate the effect of SES on healthy eating. 
TABLE 3 | Nutrition knowledge (CoNKS Total and subscales) by socio-demographic groupa in participants of the NEMONIT study $2014 / 15^{\text {b }}$.

\begin{tabular}{|c|c|c|c|c|c|c|c|c|}
\hline & \multicolumn{2}{|c|}{ CoNKS total ${ }^{c}$} & \multicolumn{2}{|c|}{ Procedural knowledge $^{d}$} & \multicolumn{2}{|c|}{ Knowledge on nutrients ${ }^{d}$} & \multicolumn{2}{|c|}{ Knowledge on calories ${ }^{e}$} \\
\hline & Mean & $P$ & Mean & $P$ & Mean & $P$ & Mean & $P$ \\
\hline Total sample & 14.1 & & 4.9 & & 4.8 & & 4.4 & \\
\hline Sex & & $<0.001$ & & $<0.001$ & & 0.006 & & 0.689 \\
\hline Males & 13.6 & & 4.6 & & 4.7 & & 4.4 & \\
\hline Females & 14.4 & & 5.1 & & 4.9 & & 4.4 & \\
\hline Age groups & & $<0.001$ & & $<0.001$ & & $<0.001$ & & $<0.001$ \\
\hline $22-34$ years & 15.3 & & 5.6 & & 5.0 & & 4.7 & \\
\hline $35-50$ years & 14.7 & & 5.2 & & 5.0 & & 4.5 & \\
\hline $51-64$ years & 14.4 & & 5.0 & & 4.9 & & 4.5 & \\
\hline $65-80$ years & 13.0 & & 4.3 & & 4.5 & & 4.2 & \\
\hline School education & & $<0.001$ & & $<0.001$ & & $<0.001$ & & $<0.001$ \\
\hline Up to 9 years & 12.5 & & 4.1 & & 4.2 & & 4.1 & \\
\hline 10 years & 14.2 & & 4.9 & & 4.8 & & 4.4 & \\
\hline 12 or 13 years & 15.0 & & 5.3 & & 5.1 & & 4.5 & \\
\hline SES class & & $<0.001$ & & $<0.001$ & & $<0.001$ & & $<0.001$ \\
\hline Low & 12.2 & & 4.1 & & 4.1 & & 4.1 & \\
\hline Medium & 13.9 & & 4.8 & & 4.7 & & 4.4 & \\
\hline High & 14.9 & & 5.3 & & 5.1 & & 4.5 & \\
\hline
\end{tabular}

a Mann-Whitney U-test (variables with two levels) or Kruskal-Wallis test (variables with more than two levels).

${ }^{b}$ NEMONIT study, survey year 2014/2015 ( $\left.n=1,505\right)$; SES, socio-economic status; CoNKS, consumer nutrition knowledge scale.

${ }^{c}$ CoNKS Total scale ranges from 0 (no question answered correctly) to 20 (all questions answered correctly).

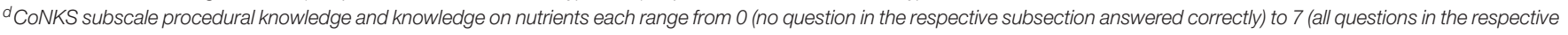
subsection answered correctly).

${ }^{e}$ CoNKS subscale knowledge on calories ranges from 0 (no question in this subsection answered correctly) to 6 (all questions in this subsection answered correctly).

\section{DISCUSSION}

This analysis of nutrition knowledge in adults based on NEMONIT and using an adapted version of the CoNKS showed several key results:

(1) Areas for knowledge enhancement could be observed in the assessment of the health benefits of fruit and vegetable consumption, in the understanding of the concept of a balanced diet as well as regarding the knowledge on saturated fatty acids.

(2) Nutrition knowledge was higher among individuals who were female, younger, had higher SES or showed a more health conscious lifestyle.

(3) Nutrition knowledge was positively associated with a favorable food consumption.

(4) Analyses of subscales of nutrition knowledge yielded similar results for procedural nutrition knowledge and knowledge on nutrients but not for knowledge on calories.

\section{Areas for Knowledge Enhancement}

In accordance with the results from Dickson-Spillmann et al. (2), the present results indicate that the health benefits of fruit and vegetable consumption do not seem to be sufficiently well-known to the public. This is unexpected since in Germany, as in many other countries, large efforts have been made to promote the consumption of fruit and vegetables, which is below the official recommendations. Hence, improved strategies are needed to communicate the (numerous) advantages of fruit and vegetables and to increase knowledge as basis for intention and action to promote their consumption.

Also in agreement with Dickson-Spillmann et al. (2), the present results showed that knowledge concerning the composition of a healthy and balanced diet could be improved. Much educational work has been done in this area, too. Among others, food circles or pyramids are a common way to present the principles of a balanced diet and are usually well disseminated and known to the public $(31,32)$. However, consumers seem to have difficulties to keep in mind, interpret, and apply these principles $(33,34)$. Nutrition education in this area might benefit from providing more common and practically relevant examples.

Additionally, knowledge on saturated fatty acids seems relatively low. This result reinforces international findings ascertaining knowledge deficits with regard to types of dietary fats $(35,36)$. Types of fat, their health implications and their sources could be another focus of nutrition education initiatives.

Although this research identified some important areas to address in nutrition education, it simultaneously indicates that an increase in nutrition knowledge alone will not substantially improve dietary behavior (see below).

\section{Associations of Socio-demographic and Lifestyle Factors With Nutrition Knowledge}

That nutrition knowledge is higher in women, normal weight and physically active persons as well as among those with higher 
TABLE 4 | Nutrition knowledge (CoNKS Total and subscales) by nutrition and health behaviour ${ }^{\mathrm{a}}$ in participants of the NEMONIT study $2014 / 15^{\mathrm{b}}$.

\begin{tabular}{|c|c|c|c|c|c|c|c|c|}
\hline & \multicolumn{2}{|c|}{ CoNKS Total } & \multicolumn{2}{|c|}{ Procedural knowledge } & \multicolumn{2}{|c|}{ Knowledge on nutrients } & \multicolumn{2}{|c|}{ Knowledge on calories } \\
\hline & Mean & $\boldsymbol{P}$ & Mean & $P$ & Mean & $P$ & Mean & $\boldsymbol{P}$ \\
\hline $\begin{array}{l}\text { Vegetarian (incl. } \\
\text { pesco-vegetarian) diet }\end{array}$ & & $<0.001^{\dagger}$ & & $<0.001^{\dagger}$ & & $<0.001^{\dagger}$ & & 0.604 \\
\hline Yes & 16.1 & & 6.1 & & 5.6 & & 4.5 & \\
\hline No & 14.0 & & 4.9 & & 4.8 & & 4.4 & \\
\hline $\begin{array}{l}\text { Dieting (e.g., to lose weight or } \\
\text { due to an illness) }\end{array}$ & & 0.016 & & 0.036 & & 0.131 & & 0.083 \\
\hline Yes & 13.3 & & 4.5 & & 4.6 & & 4.2 & \\
\hline No & 14.1 & & 4.9 & & 4.8 & & 4.4 & \\
\hline Healthiness of diet & & 0.182 & & 0.105 & & 0.173 & & 0.923 \\
\hline $\begin{array}{l}\text { Very healthy/ } \\
\text { predominantly healthy }\end{array}$ & 14.1 & & 4.9 & & 4.8 & & 4.4 & \\
\hline $\begin{array}{l}\text { Less healthy/ } \\
\text { not healthy }\end{array}$ & 13.8 & & 4.7 & & 4.7 & & 4.4 & \\
\hline Subjective health status & & 0.096 & & 0.044 & & 0.200 & & 0.646 \\
\hline $\begin{array}{l}\text { Very good/ } \\
\text { good }\end{array}$ & 14.2 & & 4.9 & & 4.8 & & 4.4 & \\
\hline $\begin{array}{c}\text { Moderate/ } \\
\text { poor/very poor }\end{array}$ & 13.8 & & 4.7 & & 4.7 & & 4.4 & \\
\hline Body mass index & & $<0.001^{\dagger}$ & & $<0.001^{\dagger}$ & & $<0.001^{\dagger}$ & & 0.655 \\
\hline Normal weight & 14.6 & & 5.2 & & 5.0 & & 4.4 & \\
\hline Underweight, overweight & 13.7 & & 4.7 & & 4.7 & & 4.4 & \\
\hline Sport activities & & $<0.001^{\dagger}$ & & $<0.001^{\dagger}$ & & $<0.001$ & & 0.022 \\
\hline Active & 14.3 & & 5.0 & & 4.9 & & 4.4 & \\
\hline Inactive & 13.5 & & 4.6 & & 4.6 & & 4.3 & \\
\hline Smoking status & & 0.079 & & 0.052 & & 0.059 & & 0.355 \\
\hline Non-smoker/ex-smoker & 14.1 & & 4.9 & & 4.8 & & 4.4 & \\
\hline Smoker/occasional smoker & 13.7 & & 4.7 & & 4.6 & & 4.4 & \\
\hline
\end{tabular}

aMann-Whitney U-test.

${ }^{b}$ NEMONIT study, survey year 2014/2015 ( $\left.n=1,505\right)$; CoNKS, consumer nutrition knowledge scale.

† Significant difference confirmed in multiple linear regression analyses controlling for sex, age in years, and socio-economic status.

socio-economic status (or its indicators such as education or employment status) has already been observed in a number of earlier studies and was discussed previously $(8,10,36-39)$.

The relationship between age and nutrition knowledge, however, was contradictory across studies $(2,8-10)$. Here, similar to Dickson-Spillmann et al. (2), age was negatively associated with nutrition knowledge. The CoNKS assessed knowledge based on insights and recommendations of the last years, e.g., to correctly reject the item "Fat is always bad for your health; you should therefore avoid it as much as possible" one must recognize that nowadays a distinction according to the type of fat is made. Older respondents might have more difficulties to obtain the necessary information and to integrate these into their already well-established concept of a healthy nutrition. Given the contradictory results on the association between age and nutrition knowledge, more research might be needed to examine if people in different age groups or stages of live have access to, understand and are able to practically implement the knowledge necessary to choose a healthy diet.

In this study, self-defined vegetarians (including pescovegetarians) compared to non-vegetarians had a higher nutrition knowledge. Up to now, there are only few and inconsistent studies on differences in nutrition knowledge among vegetarians and non-vegetarians (40). But Hoffman (40) argues that vegetarians often become "nutrition educators" since they are regularly confronted with nutrition-related questions, like where to get protein or iron in a vegetarian diet. However, the results of the present study should be interpreted with caution due to the low proportion of vegetarians.

\section{Associations of Nutrition Knowledge With Food Consumption and Diet Quality}

Participants with higher nutrition knowledge ate more favorable (e.g., vegetables, fruit/fruit products) and less unfavorable foods (e.g., meat/meat products) and showed a higher diet quality overall. Although significant associations in the expected direction were observed, the correlations between nutrition knowledge and food consumption were low in this study, also when compared to the validation study of the CoNKS (2). The results support those findings observing only a weak relationship between nutrition knowledge and dietary behavior (3). This 
TABLE 5 | Association between nutrition knowledge (CoNKS Total and subscales) and food consumption ( $\mathrm{g} / \mathrm{d})^{\mathrm{a}}$ in participants of the NEMONIT study 2014/15 ${ }^{\mathrm{b}}$.

\begin{tabular}{|c|c|c|c|c|c|c|c|c|}
\hline & \multicolumn{2}{|c|}{ CoNKS Total } & \multicolumn{2}{|c|}{ Procedural knowledge } & \multicolumn{2}{|c|}{ Knowledge on nutrients } & \multicolumn{2}{|c|}{ Knowledge on calories } \\
\hline & $r_{s}$ & $P$ & $r_{s}$ & $P$ & $r_{s}$ & $P$ & $r_{s}$ & $P$ \\
\hline Bread & 0.00 & 0.958 & -0.03 & 0.227 & 0.03 & 0.227 & -0.00 & 0.984 \\
\hline $\begin{array}{l}\text { Cereals and cereal } \\
\text { products }\end{array}$ & 0.11 & $<0.001$ & 0.14 & $<0.001$ & 0.07 & 0.006 & 0.02 & 0.394 \\
\hline $\begin{array}{l}\text { Potatoes and potato } \\
\text { products }\end{array}$ & -0.06 & 0.029 & -0.05 & 0.046 & -0.00 & 0.860 & -0.07 & $0.004^{\dagger}$ \\
\hline Vegetables $^{c}$ & 0.09 & $<0.001^{\dagger}$ & 0.11 & $<0.001^{\dagger}$ & 0.11 & $<0.001^{\dagger}$ & -0.04 & 0.173 \\
\hline Fruit and fruit products & 0.10 & $<0.001^{\dagger}$ & 0.10 & $<0.001^{\dagger}$ & 0.09 & $<0.001^{\dagger}$ & 0.01 & 0.630 \\
\hline $\begin{array}{l}\text { Milk, dairy products, } \\
\text { and cheese }\end{array}$ & 0.12 & $<0.001^{\dagger}$ & 0.07 & 0.009 & 0.13 & $<0.001^{\dagger}$ & 0.06 & 0.023 \\
\hline Eggs & 0.01 & 0.590 & -0.01 & 0.635 & 0.03 & 0.300 & 0.02 & 0.514 \\
\hline Meat, meat products & -0.14 & $<0.001^{\dagger}$ & -0.14 & $<0.001^{\dagger}$ & -0.11 & $<0.001^{\dagger}$ & -0.05 & 0.070 \\
\hline $\begin{array}{l}\text { Fish, fish products, and } \\
\text { seafood }\end{array}$ & 0.03 & 0.194 & 0.03 & 0.259 & 0.05 & 0.077 & -0.01 & 0.588 \\
\hline
\end{tabular}

aspearman's Rho correlations.

${ }^{b}$ NEMONIT study, survey year 2014/2015 (n=1,505); CoNKS, consumer nutrition knowledge scale.

cIncluding vegetable products, mushrooms, and pulses.

† Significant association confirmed in multiple linear regression analyses controlling for sex, age in years, and socio-economic status index.

indicates that an increase in nutrition knowledge alone seems unlikely to provoke large improvements in dietary behavior. Dietary behavior is complex and influenced by a number of different factors (41).

\section{Types of Nutrition Knowledge}

The separate analysis of procedural knowledge and knowledge on nutrients provided similar results as the analysis of nutrition knowledge in total. Knowledge on calories, however, seems to be a different kind of knowledge. Research on different types of knowledge is rare, but Grunert et al. (42) also observed that knowledge on the calorie content of foods was unrelated to knowledge on dietary recommendations and sources of nutrients. For future studies it might be helpful to examine the construct of nutrition knowledge and its dimensions more closely to get a better understanding of which types of knowledge might be relevant for a healthy dietary behavior in the population.

According to our results, knowledge on calories does not seem helpful in making healthy food choices. Contrary to what we would theoretically expect, it was not associated with BMI either. Knowledge on the caloric content of macronutrients, foods and meals might be too technical to be translated into a diet with adequate energy intake. Our results suggest that it might be advisable to include more information on, for e.g., the contribution of a meal to a balanced diet, in the commonly used media rather than just information on calories.

\section{Strengths and Limitations}

This study has several strengths. First, it explored nutrition knowledge based on a large sample of the German adult population. This allowed using multivariate analyses to examine group differences and associations independent from socio-demographic factors. Second, the study used a scale which showed a good ability to distinguish between nutrition-literate and lay respondents. Although some essential modifications were made, low associations between nutrition knowledge and dietary behavior are unlikely to result from incapacity of the scale to distinguish between participants with different grades of nutrition knowledge. The measurement also allowed investigating both declarative and procedural nutrition knowledge. Low associations therefore cannot be attributed to a mere assessment of declarative knowledge, which was assumed by some authors to have a lower relevance for dietary behavior $(2,3)$. Third, food consumption was assessed with two 24-h recalls, which is in accordance with the requirements of the European Food Safety Authority regarding collection of national food consumption data (43). Fourth, the healthy eating index was calculated from actual food consumption as an outcome variable to represent compliance with dietary guidelines. This was supposed to be an outcome more closely related to nutrition knowledge, but still associations prove to be low.

Some limitations of the study also need to be considered. First, the study sample was biased toward women, older persons and persons with a higher SES (23) and respondents who took part in NEMONIT for several years might be especially interested in nutrition topics. Based on this sample, nutrition knowledge might be overestimated and the discussed deficits in nutrition knowledge might be higher in the general population.

Second, the measurement of nutrition knowledge includes some uncertainties. Although nutrition knowledge was measured using a previously validated instrument, Cronbach's Alpha, which is used to assess the internal consistency of a scale, was low $(\alpha=0.59)$. The value could not be substantially increased by deleting an item and the correlations between some items were very low. This could indicate that nutrition knowledge is a heterogeneous construct with different dimensions. Another 
TABLE 6 | Associations of socio-demographic characteristics and nutrition knowledge (CoNKS Total and selected subscales) with HEI-NVS $\|^{\mathrm{a}}$ in participants of the NEMONIT study $2014 / 15^{\mathrm{b}}$.

\begin{tabular}{|c|c|c|}
\hline & $\begin{array}{l}\text { Unstandardized } \\
\text { regression } \\
\text { coefficient }\end{array}$ & $\boldsymbol{P}$ \\
\hline \multicolumn{3}{|c|}{ Model: socio-demographic characteristics only (Adj. $R^{2}=0.024$ ) } \\
\hline Female sex & 2.986 & $<0.001$ \\
\hline Age (in years) & 0.055 & 0.003 \\
\hline SES index & 0.177 & 0.019 \\
\hline \multicolumn{3}{|c|}{$\begin{array}{l}\text { Model: socio-demographic characteristics and nutrition knowledge } \\
\text { (CoNKS Total) (Adj. } R^{2}=0.051 \text { ) }\end{array}$} \\
\hline Female sex & 2.391 & $<0.001$ \\
\hline Age (in years) & 0.080 & $<0.001$ \\
\hline SES index & 0.023 & 0.760 \\
\hline CoNKS Total & 0.620 & $<0.001$ \\
\hline \multicolumn{3}{|c|}{$\begin{array}{l}\text { Model: socio-demographic characteristics and CoNKS subscale } \\
\text { procedural knowledge (Adj. } R^{2}=0.043 \text { ) }\end{array}$} \\
\hline Female sex & 2.407 & $<0.001$ \\
\hline Age (in years) & 0.077 & $<0.001$ \\
\hline SES index & 0.065 & 0.400 \\
\hline Procedural knowledge & 0.924 & $<0.001$ \\
\hline \multicolumn{3}{|c|}{$\begin{array}{l}\text { Model: socio-demographic characteristics and CoNKS subscale } \\
\text { knowledge on nutrients (Adj. } R^{2}=0.051 \text { ) }\end{array}$} \\
\hline Female sex & 2.630 & $<0.001$ \\
\hline Age (in years) & 0.064 & $<0.001$ \\
\hline SES index & 0.052 & 0.500 \\
\hline Knowledge on nutrients & 1.289 & $<0.001$ \\
\hline
\end{tabular}

a Multiple linear regression analysis with HEI-NVS II as dependent and socio-demographic characteristics and nutrition knowledge (CoNKS Total), respectively, CoNKS subscales procedural knowledge and knowledge on nutrients as independent variables.

${ }^{b}$ NEMONIT study, survey year 2014/2015 ( $n=1,505$ ); SES, socio-economic status; CoNKS, consumer nutrition knowledge scale; HEI-NVS II, Healthy Eating Index of the German National Nutrition Survey II.

possible explanation for a low Cronbach's Alpha would be a very homogenous sample. As previously mentioned, NEMONIT respondents might consistently have a higher interest in nutrition topics. Nutrition knowledge in the sample was high with a relatively low standard deviation. This might restrict the ability of the study to find large associations between nutrition knowledge and dietary behavior.

Finally, it is important to note that no causal relationships can be implied from the cross-sectional analysis.

\section{CONCLUSION}

The present study identified areas for knowledge enhancement in the assessment of the health benefits of fruit and vegetable

\section{REFERENCES}

1. Austel A, Mickelat S, Heseker H, Ellrott T. Ernährungswissen in Deutschland. Eine repräsentative Studie [Nutritional knowledge in Germany. A representative study.]. Ernährungs Umschau. (2011) 58:304-11. consumption, in the understanding of the concept of a balanced diet as well as regarding the knowledge on saturated fatty acids. These topics might be most relevant for future nutrition education efforts. However, this study also supports a number of previous studies observing significant but weak associations between nutrition knowledge and dietary behavior. This indicates that an increase in nutrition knowledge through nutrition education alone is unlikely to provoke large improvements in dietary behavior. From health and sustainability literature, it is well-known that knowledge is usually not directly translated into action. Instead, behavior is complex and influenced by a number of different factors. Research should find ways to address the complexity of dietary behavior and to identify the most important factors that need to be addressed to improve dietary behavior of the population.

\section{DATA AVAILABILITY STATEMENT}

The datasets presented in this article are not readily available because according to the regulations for the use of NVS IIand NEMONIT-study data, the datasets of the NEMONIT study are only available for universities, public and/or publicly funded scientific research institutions. Furthermore, a general essential prerequisite is the pure scientific use of the data, excluding any commercial use of the data and of the derived results. Requests to access the datasets should be directed to the corresponding author, ingrid.hoffmann@mri.bund.de.

\section{ETHICS STATEMENT}

Ethical review and approval was not required for the study on human participants in accordance with the local legislation and institutional requirements. The patients/participants provided their written informed consent to participate in this study.

\section{AUTHOR CONTRIBUTIONS}

FK analyzed and interpreted the data and drafted the manuscript. IH was involved in data interpretation and manuscript preparation. EC initiated and conceptualized the research, was involved in data interpretation and manuscript preparation and was responsible for the final content. All authors read and approved the final version of the manuscript.

\section{FUNDING}

NEMONIT was funded by the German Federal Ministry of Food and Agriculture. The ministry had no role in the design, analysis, or writing of this article.
2. Dickson-Spillmann M, Siegrist M, Keller C. Development and validation of a short, consumer-oriented nutrition knowledge questionnaire. Appetite. (2011) 56:617-20. doi: 10.1016/j.appet.2011.01.034

3. Spronk I, Kullen C, Burdon C, O'Connor H. Relationship between nutrition knowledge and dietary intake. $\mathrm{Br} J$ 
Nutr. (2014) 111:1713-26. doi: $\quad 10.1017 /$ S000711451400 0087

4. Serra-Majem L, Ribas-Barba L, Salvador G, Serra J, Castell C, Cabezas C, et al. Compliance with dietary guidelines in the catalan population: basis for a nutrition policy at the regional level (the PAAS strategy). Public Health Nutr. (2007) 10:1406-14. doi: 10.1017/S1368980007001012

5. Krebs-Smith SM, Guenther PM, Subar AF, Kirkpatrick SI, Dodd KW. Americans do not meet federal dietary recommendations. J Nutr. (2010) 140:1832-8. doi: 10.3945/jn.110.124826

6. Black JL, Billette J-M. Do Canadians meet Canada's food guide's recommendations for fruits and vegetables? Appl Physiol Nutr Metab. (2013) 38:234-42. doi: 10.1139/apnm-2012-0166

7. Heuer T, Krems C, Moon K, Brombach C, Hoffmann I. Food consumption of adults in Germany: results of the German national nutrition survey II based on diet history interviews. Br J Nutr. (2015) 113:1603-14. doi: 10.1017/S0007114515000744

8. Hendrie GA, Coveney J, Cox D. Exploring nutrition knowledge and the demographic variation in knowledge levels in an Australian community sample. Public Health Nutr. (2008) 11:1365-71. doi: $10.1017 /$ S1368980008003042

9. Dickson-Spillmann M, Siegrist M. Consumers' knowledge of healthy diets and its correlation with dietary behaviour. J Hum Nutr Diet. (2011) 24:54-60. doi: 10.1111/j.1365-277X.2010.01124.X

10. Parmenter K, Waller J, Wardle J. Demographic variation in nutrition knowledge in England. Health Educ Res. (2000) 15:163-74. doi: 10.1093/her/15.2.163

11. Parmenter K, Wardle J. Development of a general nutrition knowledge questionnaire for adults. Euro J Clin Nutr. (1999) 53:298-308. doi: $10.1038 /$ sj.ejcn. 1600726

12. Kliemann N, Wardle J, Johnson F, Croker H. Reliability and validity of a revised version of the General Nutrition Knowledge Questionnaire. European journal of clinical nutrition. (2016) 70:1174-80. doi: 10.1038/ejcn. 2016.87

13. Matsumoto M, Tanaka R, Ikemoto S. Validity and reliability of a general nutrition knowledge questionnaire for Japanese adults. J Nutr Sci Vitaminol. (2017) 63:298-305. doi: 10.3177/jnsv.63.298

14. Thompson C, Vidgen HA, Gallegos D, Hannan-Jones MT. Validation of a revised general nutrition knowledge questionnaire for Australia. Public Health Nutr. (2019) 1-11. doi: 10.1017/S13689800190 05135

15. Putnoky S, Banu AM, Moleriu LC, Putnoky S, Şerban DM, Niculescu MD, et al. Reliability and validity of a general nutrition knowledge questionnaire for adults in a Romanian population. Euro J Clin Nutr. (2020) 74:1576-84. doi: 10.1038/s41430-020-0616-5

16. Mikhail D, Rolls B, Yost K, Balls-Berry J, Gall M, Blixt K, et al. Development and validation testing of a weight management nutrition knowledge questionnaire for adults. Int J Obes. (2020) 44:579-89. doi: 10.1038/s41366-019-0510-1

17. Rosi A, Ferraris C, Guglielmetti M, Meroni E, Charron M, Menta R, et al. Validation of a general and sports nutrition knowledge questionnaire in Italian early adolescents. Nutrients. (2020) 12:3121. doi: 10.3390/nu121 03121

18. Rosi A, Martini D, Grosso G, Bonaccio ML, Scazzina F, Angelino D. Validation of a nutrition knowledge questionnaire in Italian students attending the University of Parma. Public Health Nutr. (2020) 23:1527-31. doi: 10.1017/S1368980019004555

19. Vázquez-Espino K, Fernández-Tena C, Lizarraga-Dallo MA, FarranCodina A. Development and validation of a short sport nutrition knowledge questionnaire for athletes. Nutrients. (2020) 12:3561. doi: 10.3390/nu12113561

20. Worsley A. Nutrition knowledge and food consumption: can nutrition knowledge change food behaviour? Asia Pac J Clin Nutr. (2002) 11:S579-85. doi: 10.1046/j.1440-6047.11.supp3.7.x

21. MRI. (2008). Nationale Verzehrsstudie II. Ergebnisbericht, Teil 1 mit Ergänzungsband [National Nutrition Survey II. First Report With Supplement]. Karlsruhe: MRI.

22. Gose M, Krems C. Ernährungswissen: Determinanten und Entwicklungen - Ergebnisse des Nationalen Ernährungsmonitorings (NEMONIT)
[Nutrition knowledge: determinants and trends - results of the German national nutrition monitoring (NEMONIT)]. In: Abstractband zum 53 Wissenschaftlichen Kongress der DGE [Abstract book of the 53 Scientific Congress of the German Nutrition Society]. Fulda: German Nutrition Society (2016). p. 79.

23. Gose M, Krems C, Heuer T, Hoffmann I. Trends in food consumption and nutrient intake in Germany between 2006 and 2012: results of the German national nutrition monitoring (NEMONIT). Br J Nutr. (2016) 115:1498-507. doi: 10.1017/S0007114516000544

24. WHO. Obesity: Preventing and Managing the Global Epidemic. Report of a WHO Consultation. Geneva: WHO (2000).

25. WHO. Global Recommendations on Physical Activity for Health. Geneva: WHO (2010).

26. Slimani N, Deharveng G, Charrondière RU, Van Kappel AL, Ocké MC, Welch A, et al. Structure of the standardized computerized 24-h diet recall interview used as reference method in the 22 centers participating in the EPIC project. Comput Methods Programs Biomed. (1999) 58:251-66. doi: 10.1016/S0169-2607(98)00088-1

27. Hartmann BM, Heuer T, Hoffmann I. The German nutrient database: effect of different versions on the calculated energy and nutrient intake of the German population. J Food Composit Anal. (2015) 42:26-9. doi: 10.1016/j.jfca.2015.01.001

28. Oberritter H, Schäbethal K, Von Ruesten A, Boeing H. The DGE nutrition circle-Presentation and basis of the food-related recommendations from the German nutrition society (DGE). Ernaehrungs Umschau Int. (2013) 60:24-9.

29. DGE, ÖGE, and SGE. Referenzwerte Für die Nährstoffzufuhr [Reference Values for Nutrient Intake]. Bonn: German Nutrition Society, Austrian Nutrition Society, Swiss Nutrition Society (2015).

30. Wittig F, Hoffmann I. Ernährungsmuster von Bio-Käufern und NichtBio-Käufern [Dietary patterns of buyers and nonbuyers of organic food]. In: Hoffmann I, Spiller A, editors. Auswertung der Daten der Nationalen Verzehrsstudie II (NVS II): eine integrierte verhaltens- und lebensbasierte Analyse des Bio-Konsums [Data Interpretation Based on the German National Nutrition Survey II (NVS II): An Integrative Analysis of Behavioural and Lifestyle-Related Factors for Organic Food Consumption] Karlsruhe/Göttingen: Max Rubner-Institut/Georg-August-University Göttingen (2010). p. 51-68.

31. Bechthold A, Boeing H, Tetens I, Schwingshackl L, Nöthlings U. Perspective: food-based dietary guidelines in Europe-scientific concepts, current status, and perspectives. Adv Nutr. (2018) 9:544-60. doi: 10.1093/advances/ nmy033

32. Herforth A, Arimond M, Álvarez-Sánchez C, Coates J, Christianson K, Muehlhoff E. A global review of food-based dietary guidelines. Adv Nutr. (2019) 10:590-605. doi: 10.1093/advances/nmy130

33. Brown KA, Timotijevic L, Barnett J, Shepherd R, Lähteenmäki L, Raats MM. A review of consumer awareness, understanding and use of food-based dietary guidelines. Br J Nutr. (2011) 106:15-26. doi: 10.1017/S00071145110 00250

34. Bechthold A, Wendt I, Laubach B, Mayerböck C, Oberritter H, Nöthlings U. Consumers' awareness of food-based dietary guidelines in Germany. Results of a representative survey. Ernahrungs Umschau. (2017) 64: 112-9.

35. Diekman C, Malcolm K. Consumer perception and insights on fats and fatty acids: knowledge on the quality of diet fat. Ann Nutr Metab. (2009) 54 (Suppl. 1):25-32. doi: 10.1159/000220824

36. Harbury CM, Callister R, Collins CE. Nutrition "fat facts" are not common knowledge. Health Promot J Austr. (2018) 29:93-9. doi: 10.1002/hpja.6

37. Wardle J, Parmenter K, Waller J. Nutrition knowledge and food intake. Appetite. (2000) 34:269-75. doi: 10.1006/appe.1999.0311

38. Bonaccio M, Di Castelnuovo A, Costanzo S, De Lucia F, Olivieri M, Donati $\mathrm{MB}$, et al. Nutrition knowledge is associated with higher adherence to mediterranean diet and lower prevalence of obesity. Results from the molisani study. Appetite. (2013) 68:139-46. doi: 10.1016/j.appet.2013.04.026

39. Jeruszka-Bielak M, Kollajtis-Dolowy A, Santoro A, Ostan R, Berendsen AA, Jennings A, et al. Are nutrition-related knowledge and attitudes reflected in lifestyle and health among elderly people? A study across five European countries. Front Physiol. (2018) 9:994. doi: 10.3389/fphys.2018.00994

40. Hoffman SR. Nutrition knowledge of vegetarians. In: Mariotti F, editor. Vegetarian and Plant-Based Diets in Health and Disease 
Prevention. London; San Diego; Cambridge; Oxford: Elsevier (2017). p. 37-50.

41. Hummel E, Hoffmann I. Complexity of nutritional behavior: capturing and depicting its interrelated factors in a cause-effect model. Ecol Food Nutr. (2016) 55:241-57. doi: 10.1080/03670244.2015.1129325

42. Grunert KG, Wills J, Celemín LF, Lähteenmäki L, Scholderer J, Storcksdieck genannt Bonsmann S. Socio-demographic and attitudinal determinants of nutrition knowledge of food shoppers in six European countries. Food Qual Prefer. (2012) 26:166-77. doi: 10.1016/j.foodqual.2012.04.007

43. European Food Safety Authority. Guidance on the EU menu methodology. EFSA J. (2014) 12:3944. doi: 10.2903/j.efsa.2014.3944
Conflict of Interest: The authors declare that the research was conducted in the absence of any commercial or financial relationships that could be construed as a potential conflict of interest.

Copyright $\odot 2021$ Koch, Hoffmann and Claupein. This is an open-access article distributed under the terms of the Creative Commons Attribution License (CC BY). The use, distribution or reproduction in other forums is permitted, provided the original author(s) and the copyright owner(s) are credited and that the original publication in this journal is cited, in accordance with accepted academic practice. No use, distribution or reproduction is permitted which does not comply with these terms. 